\title{
Jovem escritor de gerações
}

Resumo: Recordista de vendas na literatura infantojuvenil brasileira, o escritor Pedro Bandeira fala sobre seu processo criativo e sobre a evolução de sua carreira, inteiramente dedicada aos públicos infantil e adolescente. Comenta ainda o perfil dos leitores brasileiros, as carências do cenário educacional para crianças e jovens e discute os estímulos que estes recebem, ou devem receber, ao longo da vida, para se tornarem adultos leitores.

Palavras-chave: literatura, infância, adolescência, educação.
Abstract: Sales record-breaking at children an adolescent's Brazilian literature, the writer Pedro Bandeira talks about his creative process and his career evolution, entirely dedicated to child and adolescent public. He also comments the Brazilian readers profile, the educational scenery shortages for children and young people and discusses the stimuli they receive, or shall receive, throughout life, to become adult readers.

Keywords: literature, childhood, adolescen$\mathrm{ce}$, education.

De sorriso fácil e expressão acolhedora, o escritor Pedro Bandeira, em sua simplicidade, não transparece o fenômeno literário de vendas que se tornou no Brasil - mais de 21 milhões de exemplares, ultrapassando por vezes a marca de 100 mil livros ao ano. De ator e diretor teatral no início de carreira - e depois jornalista na década de 1960 -, até se tornar um dos poucos escritores brasileiros que se mantêm exclusivamente de direitos autorais, Bandeira trilhou um caminho que passou também pelo estudo da educação, do desenvolvimento humano e do perfil da criança e do adolescente, seus públicos cativos. $O$ resultado são livros como A droga da obediência, A marca de uma lágrima ou O mistério fantástico da Feiurinha - este último transformado em filme estrelado pela apresentadora Xuxa-, que já passam à terceira geração de leitores e continuam sendo sucesso, adotados na maioria das escolas de Ensino Fundamental e utilizados por educadores em atividades pedagógicas. Neste depoimento, ele fala como decidiu dedicar a carreira à criança e ao jovem, e dos reflexos que essa escolha trouxe não só para sua carreira, mas também para sua vida pessoal.

Como jornalista, sempre trabalhei na área de texto. Escrevi para a revista Última Hora e depois, por muito tempo, estive na Editora Abril, em diversas funções - publicações técnicas, fascículos, revistas femininas. Meu último cargo na editora foi na área de marketing das publicações infantis. E lá mesmo, comecei a fazer alguns trabalhos freelances - pequenas histórias que eram publicadas nessas revistas e traziam bonequinhas de papel para as meninas recortarem e vestirem, ou então de surf, para os meninos. Fazia as histórias de acordo com os temas da edição que estava para ser publicada. Quando percebi, já tinha escrito dezenas de histórias para revistas vendidas em bancas. Nessa época, tinha cerca 
de quarenta anos e aquele trabalho extra ajudava a criar bem os meus três filhos.

Foi então que minha grande amiga Marisa Lajolo, conhecida escritora e acadêmica na área de literatura, me encorajou a explorar ainda mais esse trabalho. Ela sempre comprava para os filhos as publicações em que eu escrevia e gostava muito dos meus textos; dizia que eu deveria investir nisso. Sugeriu, assim, que eu escrevesse um livro. Pouco depois, estimulado pelas opiniões po-

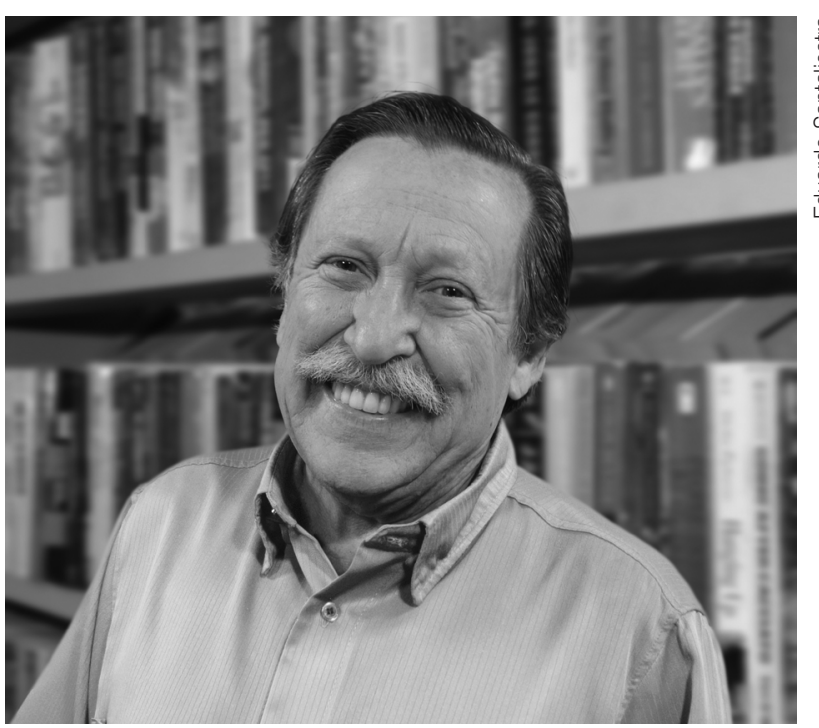

Pedro Bandeira nasceu em Santos, SP, em 09/03/1942. Em 1961, para estudar Ciências Sociais na USP, mudou-se para a capital de São Paulo. sitivas de colegas e de leitores das revistas, publiquei em 1983 meu primeiro livro infantil, $O$ dinossauro que fazia au-au. Teve um desempenho regular, mas decidi continuar a experiência. E parti para o livro seguinte, A droga da obediência, publicado em 1984. Este sim foi um best-seller e até hoje é um dos meus livros mais vendidos, tendo passado por gerações de leitores desde sua primeira edição.

A partir daí, vi na atividade de escritor uma oportunidade de liberdade. Não achei que passaria a viver dos meus livros, mas pensei que poderia, talvez, me tornar uma espécie de freelancer de textos, escrevendo para vários lugares e editoras diferentes. Decidi abandonar meu emprego fixo e viver de trabalhos de texto para publicações diversas.

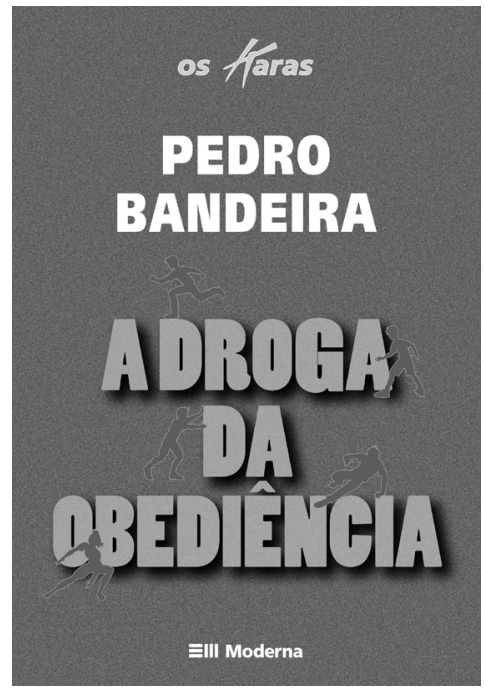

Capa: A droga da obediência.

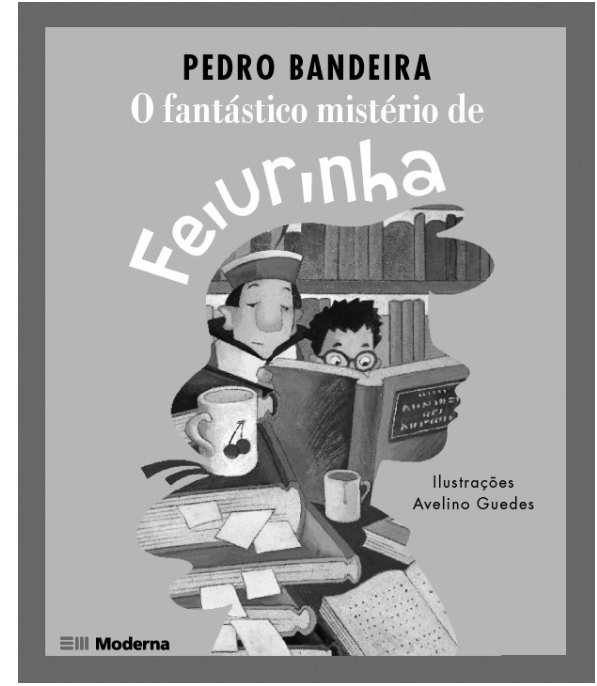

Capa: O fantástico mistério de Feiurinha. 
Apesar de não ter pensado em me dedicar integralmente à literatura, porém, logo ela me engoliu. Vieram os livros A marca de uma lágrima, em 1985, e O fantástico mistério da Feiurinha, em 1986. Atualmente, com mais de setenta livros publicados, vivo de direitos autorais. Acho que posso me considerar um autor de sorte nesse sentido, pois a maioria dos meus colegas precisa ter outros empregos além do ofício de escritor - são também jornalistas, professores universitários. Infelizmente, na maioria das profissões artísticas, isso ocorre: muitos pintam, muitos tocam piano, mas poucos se tornam exclusivamente pintores ou pianistas.

Não é comum que se consiga viver da própria arte. E o Brasil tem uma safra de excelentes escritores para o público infantojuvenil, que atualmente são publicados inclusive no exterior. $\mathrm{O}$ fato de as escolas adotarem livros infantojuvenis em seus currículos ajudou esses escritores a se firmarem, inclusive porque é muito difícil vender livros para adultos no Brasil. Sem a lei da adoção escolar, a situação do escritor brasileiro seria muito pior - até porque, quando você não tem seu trabalho bem acolhido, é muito difícil ter motivação para continuar. Acredito que muitos bons escritores desistam no meio do caminho, por não receber a acolhida esperada. Vejo muitos encontros de escritores que publicam de maneira independente, de forma artesanal e às próprias custas, para poderem existir na cena literária. Publicam principalmente para exercer a arte.

No Brasil, temos essa legislação específica que prevê a utilização de obras de literatura no currículo do ensino infantil e juvenil. É bom que seja assim, porque o brasileiro não tem, infelizmente, a cultura de comprar livros. Que eu saiba, uma lei deste tipo só existe aqui, e eu acredito que os autores juvenis só existem porque ela existe. É claro que, se a criança não receber livros que a agradem, não continuará lendo depois - será um leitor por obrigação, dentro da sala de aula. E na verdade, para que se forme um futuro leitor, o trabalho tem que começar muito antes. A escola recebe a criança tarde para desempenhar essa tarefa. A criança chega à sala de aula com uma média de quatro anos de idade, enquanto o período crucial para sua formação psicológica acontece antes, até os três anos. Sendo assim, é da família o papel fundamental no desenvolvimento do hábito da leitura. Os pais precisam contar histórias, comprar livros de figuras e atividades para que a criança se habitue a eles, desenvolva o gosto por conviver com a literatura. Infelizmente, as famílias no Brasil não têm o hábito de presentear as crianças com livros. Nossa tradição nisso ainda é muito fraca, basta verificar os números divulgados pelos organismos de avaliação nos últimos anos, por exemplo, em compreensão de textos, quando chegamos a ficar em último lugar*. A verdade é que nós brasileiros somos, em nossa maioria, analfabetos funcionais.

Mesmo a internet, que muitos dizem que prejudicará o hábito da leitura, exige uma capacidade mínima de compreensão de textos. Tudo na internet é escrito. Para usá-la, o aluno tem que saber ler, e ler rápido, pois é um meio de comunicação extremamente dinâmico - e exige, inclusive, que se tenha
* Em 2001, o Brasil ficou em último lugar no ranking de 32 países avaliados pelo Programa Internacional de Avaliação de Alunos (PISA), na capacidade de compreensão de textos entre a população maior de quinze anos. N.E. 
comunicação \& educação • Ano XV • número 3 • set/dez 2010

um mínimo de conhecimento da língua inglesa. Para usá-la, é necessário ser bom leitor, e essa capacidade o estudante brasileiro ainda não tem. $\mathrm{O}$ jovem brasileiro não gosta nem mesmo de assistir a filmes legendados no cinema, pois não consegue acompanhar o texto. É preciso mudar a cultura brasileira com relação à importância da escrita, de se lidar com o texto. A partir daí se conseguirá modificar muitas outras coisas também.

\section{NOS CAMINHOS DA ESCOLA}

Sempre escrevi obras para serem adotadas nas escolas, desde o início de minha carreira de escritor. Quando os livros começaram a fazer sucesso entre as crianças e os jovens, percebi que deveria estudar seriamente o público para o qual estava escrevendo. Uma criança de oito anos é muito diferente de uma de doze, por exemplo, que já começa a se envolver com dilemas da adolescência, modifica sua maneira de olhar os amigos, as relações na escola. Comecei a estudar educação e psicologia do desenvolvimento, para fazer livros mais bem dirigidos para as diferentes idades. Era preciso saber como o ser humano se desenvolve, em que momento ele se desliga do pai e da mãe, a partir de quando começa a dar mais importância às opiniões dos amigos e assim por diante. Hoje, depois de estudar a área,

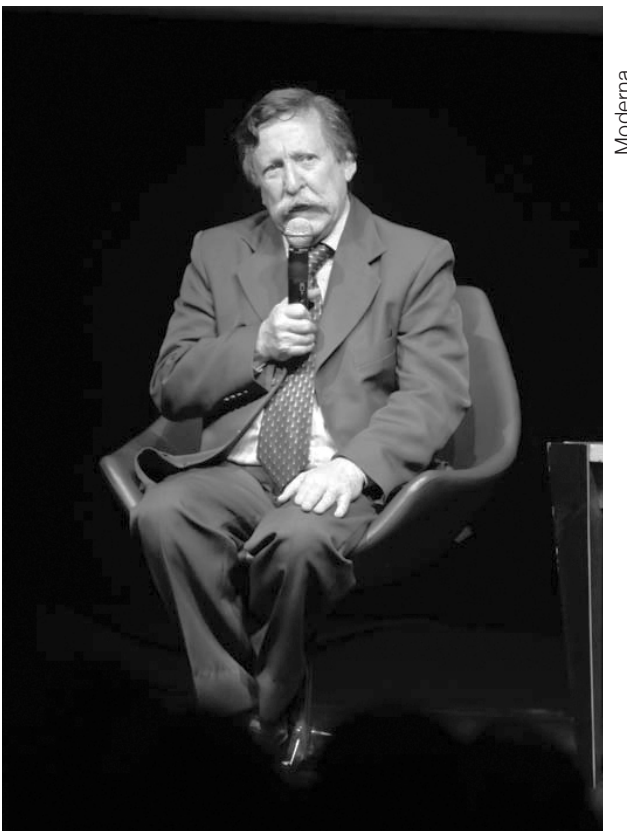

Desde 1972, Pedro Bandeira tem atuado como escritor de literatura para crianças e jovens, pesquisador e conferencista sobre literatura, educação e psicologia do desenvolvimento. consigo saber melhor quando um livro

é funcional para esta ou aquela idade específica. Esses anos de estudo fizeram, também, com que eu pudesse dar palestras nas escolas a respeito de psicologia do desenvolvimento. Tenho viajado bastante pelo Brasil falando sobre o assunto, aliado à minha experiência como escritor.

Apesar de ter mais subsídios e informações para escrever para crianças e jovens, acredito que o processo de criação do autor é sempre, fundamentalmente, intuitivo. Para escrever, a inspiração vem de diferentes maneiras e dos lugares e situações mais variados. Um dia, por exemplo, vi um cachorro manso, muito dócil, que se deixava acariciar e brincava com quem se aproximasse. Pensei: "E se esse cachorro miasse?". Nasceu assim o livro É proibido miar, sobre um cachorro que mia e que passa por vários problemas por ser diferente dos outros. Outro exemplo: sempre gostei muito da história de Cyrano de Bergerac, um livro do autor francês Edmond Rostand, no qual um jovem feio, mas extremamente talentoso com as palavras, ajuda a conquistar seu grande amor para o 
Jovem escritor de gerações - Juliana Winkel

amigo, por meio de cartas. Achei que poderia adaptá-la para um livro, e assim nasceu A marca de uma lágrima, que é a mesma história se passando com dois adolescentes. Sempre gostei muito também de Shakespeare, especialmente de Hamlet. Hamlet ao contrário se lê Telmah. Assim escrevi Agora estou sozinha..., que é a história de Hamlet vivida pela jovem Telmah.

$\mathrm{Na}$ verdade, uma pequena ideia pode ser o gatilho para uma história, mas sua existência real depende de muito trabalho. É preciso reescrever, revisar, analisar e escrever de novo, muitas vezes. É o trabalho do escritor que faz um livro; o talento é uma pequeníssima parte do ofício do artista. Acho que por isso meu processo de criação é demorado: reescrevo muitas vezes, costumo ser bastante crítico com o meu trabalho. Alguns livros demoram até quatro anos para ficar prontos. A gente começa a escrever, para por um período, depois retoma. E ao longo do tempo, vou construindo os elementos da história, construindo os personagens. Se for escrever sobre uma menina de doze anos, preciso saber como uma menina de doze anos fala, como se relaciona. Preciso saber que nessa idade as meninas estão ficando mocinhas, brigam mais com as mães do que antes, têm turmas de amigas inseparáveis. Se eu fizer um livro com personagens que não se parecem com os adolescentes reais, a obra será um fracasso. $\mathrm{O}$ adolescente não gosta de se sentir sozinho, por exemplo. Tem de ter uma turma de amigos forte para dividir os acontecimentos. Além disso, é necessário saber como contar, para que a história fique interessante. Se eu usar a terceira pessoa, por exemplo, não vai prender o leitor. O narrador em terceira pessoa é o adulto que sabe tudo, e se há um adulto que sabe tudo na história, o livro não tem surpresas. É essencial criar uma expectativa, deixar espaço para que o leitor pense e participe da história.

\section{NOVOS TEMPOS PARA OS LEITORES JOVENS?}

O homo sapiens se tornou o ser que é há apenas 150 mil anos, e vai demorar até que haja outra mutação. O ser humano é exatamente igual ao que era há centenas de anos - os mesmos medos, as mesmas esperanças, os mesmos anseios. Quando escrevi A droga da obediência, não havia computador. Os personagens vão até o orelhão e colocam fichas para falar com os outros e resolver os enigmas da história. E as crianças de hoje continuam lendo o livro e não estranham, simplesmente porque isso não é importante. Elas querem saber é do enredo, do que vai acontecer em seguida. Shakespeare escreveu sobre um Rei da Inglaterra que é igual a mim. Não importa se ele é rei ou em que época viveu; a história me interessa porque ele está vivendo algo que eu também vivo. O clássico Odisseia, de Homero, é a base de todos os romances modernos e continua sendo lido até hoje, pois fala das tragédias e vitórias universais do ser humano. Conta a história de um herói que, depois de muitas lutas e desafios, chegou a um final satisfatório, aprendeu algo, evoluiu. Já Dom Quixote, de Cervantes, fala de um homem que vive na passagem da Idade Média para a 
comunicação \& educação • Ano XV • número 3 • set/dez 2010

Idade Moderna e que não se adapta a essa transição. Ele acredita que ainda existem cavaleiros, que os tempos heroicos de antes não acabaram. Hoje o jovem, aos vinte e cinco anos, já é um Dom Quixote. Eu tenho um filho de quarenta anos que era meu grande consultor de informática e hoje já não domina muitos dos recursos tecnológicos atuais.

Acho que não devemos ter medo do progresso. Quando o cinema sur-

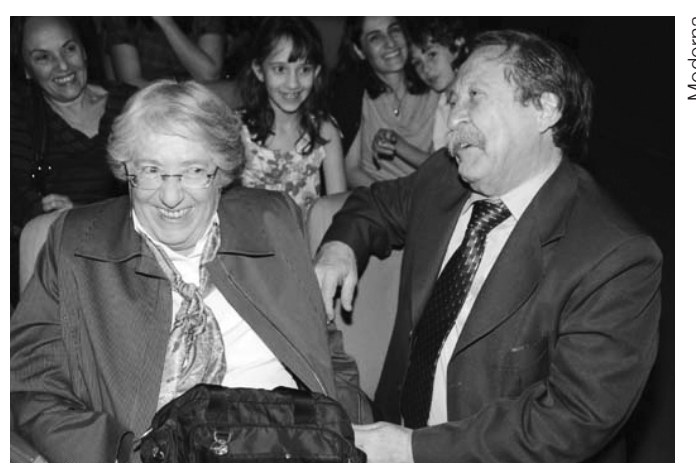

Pedro Bandeira com a esposa Lia, com que tem três filhos (Rodrigo, Maurício e Marcelo), e os netos Melissa, Michelle, Beatriz, Júlia e Érico.

giu, muitos disseram que era o fim do mundo, que isso iria arruinar a cultura. A mesma coisa aconteceu quando surgiu a televisão. Mas precisamos acompanhar o tempo presente - até porque não há escapatória e nenhuma inovação é terrível. Acredito que os livros que contam histórias universais; ao contrário de se tornarem ultrapassados, ficam mais atuais à medida que o tempo passa.

\section{VOLTA DAS LETRAS}

O retorno do público é uma das maiores gratificações do artista. Acabo de voltar da cidade de Imperatriz, no Maranhão, e tive a experiência de falar com professoras que foram minhas leitoras quando crianças. Escrevi para diferentes gerações e hoje sou lido por crianças e jovens que são filhos dos meus primeiros leitores, e que já estão tendo seus filhos, que com sorte irão ler meus livros também. Isso é muito mais recompensador do que ganhar qualquer quantia de dinheiro, assim como quando alguém me diz: "Eu não gostava de ler, mas depois de ler um livro seu, agora gosto" ou "Comecei a ler por sua causa".

Certa vez, uma professora me contou sobre uma classe sua que tinha alunos muito renitentes à leitura e mesmo às atividades em sala de aula, de maneira geral. Um dia, antes de começar a aula, ela entrou na sala e estavam todos sentados, em silêncio, lendo A droga da obediência. Pediram que ela esperasse um pouco antes de começar a aula, até que terminassem de ler o capítulo. Isso é recompensador, porque a minha intenção é despertar o prazer de ler, não só os meus livros, mas qualquer coisa. O conhecimento da humanidade está escrito. Tudo com que lidamos usa a linguagem escrita, desde obras universais até um simples manual. A escrita fez a nossa civilização; sem ela, viveríamos na barbárie. Eu tenho orgulho de ser a base da pirâmide, não o topo. Fico feliz quando alguém me diz que, por meio dos meus livros, se interessou por ler obras mais complexas, de autores clássicos, ou simplesmente tomou gosto pelo hábito da leitura e isso fez dele uma pessoa mais interessada, mais capaz de lidar com o nosso mundo. Quero que, começando por mim, os leitores possam chegar ao topo, até as grandes obras universais. Penso que, assim, estou contribuindo para fazer um país mais feliz. 